\title{
Deploy tools that are essential to the office and alchemy of healing
}

\section{CLINICAL INSIGHT}

\section{Moyez Jiwa}

The University of Notre Dame Australia, School of Medicine Sydney, Melbourne Clinical School, Werribee, VIC, Australia
To Cite: Jiwa M. Deploy tools that are essential to the office and alchemy of healing. JHD 2016;1(3):6-8.

https://doi.org/10.21853/JHD.2016.18

\section{Corresponding Author:}

\section{Prof Moyez Jiwa}

The University of Notre Dame, Australia Melbourne Clinical

School

300 Princes Highway, Werribee, VIC 3030

Australia

moyez.jiwa@nd.edu.au

\section{Copyright:}

C 2016 The Authors. Published by Archetype Health Pty Ltd..

This is an open access article under the CC BY-NC-ND 4.0 license.

\section{SUMMARY}

A simple change to the primary care consultation room can have a significant impact on the patient experience. Simply by having patients sit in the "big chair" typically reserved for the general practitioner puts the patient at the centre of attention, making both a physical and psychological impact.

\section{Key Words}

Patient experience; exam room; primary care; consultation

\section{INTRODUCTION}

Within the modern consulting room there is a desk, chairs, couch, and equipment that may or may not be on display. These "props" can be seen and felt even before the actual interaction has occurred or either "actor" has attempted to engage in the theatre that is the consultation. What is experienced by the senses can alter the interpretation of what subsequently transpires during the consultation. This brief paper describes the experience of one primary care physician who gained the impression of an improvement in the consultation merely by changing the seating arrangements and proactively examining every patient.
My consulting room is organized in a very traditional office style with the tall swiveling high-backed executive chair reserved for the doctor. I swapped the seating arrangements around as shown in Figure 1.

In addition, I made a point of examining every patient who presented to the clinic-no matter what the reason for their attendance. Where possible, I used my stethoscope. There was always something that could be done. The person attending for a review of their depression could have their blood pressure checked. The person who needed a repeat prescription might have their weight recorded, etc. Much of this opportunistic examination is recommended, but in this case, any and every opportunity to examine the patient was taken.

\section{LESSONS LEARNED}

What I learned from this reorganization of the furniture was that many patients notice the change in seating arrangements and often comment when they are offered the "big chair". The body language of patients changed in subtle ways-they were more relaxed. As I was seated lower than the patient on a harder seat I found myself more likely to stand up, taking more time to explain things. The patient became much more the centre of attention in the room. Both physically and, I thought, psychologically.

It has been proposed that one could explore how the height of the chair can influence consumers: ${ }^{1}$ a taller chair (or chair back) signals status and authority, while a lower chair signals relative inferiority. Closely related, the actual comfort one derives from the seat of the chair (ie, is the seat hard or soft?) may influence consumers' satisfaction especially in situations where the service is experienced while one sits. I gained the impression that patients were more satisfied with the consultation. Some patients asked why I wasn't sitting in the big chair and when I explained that they were the one who was important, insofar as they were the one who was sick, they expressed appreciation for what they considered a thoughtful gesture. 
The stethoscope has been referred to as the "umbilical cord of medicine", uniting doctor and patient. ${ }^{1}$ The stethoscope, and its use in the medical examination, has become iconic of "doctors" and their work. Every doctor recalls the sense of initiation into a special group when $\mathrm{s} /$ he acquired his/her first stethoscope. Porter identified a long tradition of the doctor being a practitioner of "bedside medicine", an idea that can be traced back to antiquity. ${ }^{2} \mathrm{He}$ noted that the ideal of an intimate physician-patient relationship was fostered even in medieval times. The doctor was involved in close, face-toface contact with the patient. S/he is directly implicated in the patient's suffering, or at least, as Berger suggested, 'bears witness' to it. ${ }^{4}$ Porter pointed out that much is made of the significance of this personal touch in medicine, the face-to-face relationship even being considered "essential to the office and alchemy of healing". 3

In a recent study where images of an individual were presented carrying medical equipment, it was shown that the stethoscope was more likely to be present in images where the person in the photograph was regarded as one or more of honest, trustworthy, honorable, moral, ethical, or genuine. ${ }^{5}$ This was particularly true in images that contained only one piece of equipment. However, the stethoscope was also more likely to be present in images credited with any of these characteristics when multiple pieces of equipment were presented. ${ }^{5}$

Without the patients' impressions, which were not formally recorded in this exercise, it is not possible to conclude that there is a real effect to report. It is also possible that it was the proactive examination and not the seating arrangements that were more important. In other words, it was my bias that people would feel more empowered in the consultation because of the changes I had introduced. However, I have continued with this practice and my instincts suggest that the effect is real and that both elements are crucial. There is a plethora of literature on the impact of architecture on "healing" in healthcare environments:

The "ambiance" of a space has an effect on people using the space. In recent years, design for healthcare environments has begun to include esthetic enhancements in an attempt to reduce stress and anxiety, increase patient satisfaction, and promote health and healing. ${ }^{6}$
However, little has been published on the impact of the organisation of the paraphernalia within the consultation room on the patient's perceptions and subsequent actions. What has been described here is a relatively cheap innovation, which does not require much effort or investment. However, the potential impact on the dynamic of the consultation may be very profound. In this case, the chair and its position become more than somewhere to sit. It becomes as integral to the consultation as the stethoscope.

\section{CLINICIAN INSIGHT}

As a family physician, the doctor-patient relationship is vital to providing clinical care. This simple adaptation of the consultation room could have a powerful impact on the doctor-patient relationship. The swapping of chairs flips the implied balance of power from physician as the authority to the importance of the patient in this interaction.

I should note that many clinicians work in group practices that may not have a large chair(s) in the consultation room like in the example, but the existing furniture could still be examined and adapted in a similar way.

For years in my clinical teaching, I have discussed with medical trainees that the height (and position) of the doctor relative to the patient gives non-verbal messages to the patient that we cannot ignore. Further evaluation of the clinic design and its impact on the perceived care should be conducted. Similarly, the use of video review of medical trainees' interviewing can lead to important changes to the doctor-patient relationship.

\section{Dr Doug Klein MD Msc CCFP \\ Familiy Medicine \\ Canada}

\section{REFERENCES}

1. Zhu R, Argo JJ. Exploring the Impact of Various Shaped Seating Arrangements on Persuasion. Journal of Consumer Research. Aug 2013;40(2):336-49. DOI: $\quad 10.1086 / 670392$ (http://jcr.oxfordjournals.org/content/40/2/336)

2. Gerchufsky M. 'Ode to a Stethoscope, the Umbilical Cord of Health Care'. Advance. 1995;3:47-50. 
3. Porter, R. The Greatest Benefit to Mankind: A

Medical History of

Humanity from Antiquity to the Present. London: Fontana Press; 1997.

4. Berger J. A Fortunate Man: The Story of a Country Doctor. New York: Vintage Books; 1967.

5. Jiwa M, Millett S, Meng X, et al. Impact of the presence of medical equipment in images on viewers' perceptions of the trustworthiness of an individual on-screen J. Med. Internet Res. 2012;14:e100.

6. Schweitzer M, Gilpin L, Frampton S. Healing Spaces:

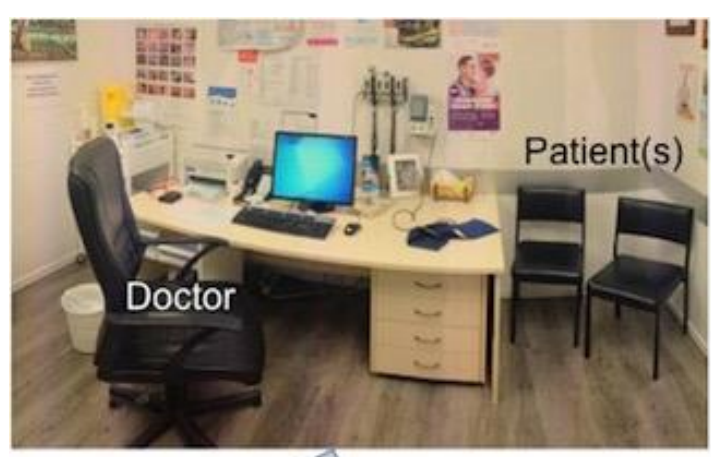

Elements of Environmental Design That Make an Impact on Health. The Journal of Alternative and Complementary Medicine. 2004;10 supplement 1:S71-S-83.

\section{ACKNOWLEDGEMENTS}

None

\section{PEER REVIEW}

Not commissioned. Externally peer reviewed.

\section{CONFLICTS OF INTEREST}

The authors declare that they have no competing interests.

\section{FUNDING}

None

\section{ETHICS COMMITTEE APPROVAL}

None

Figure 1: Repositioning the "big chair" 